\title{
ANALISIS SISTEM PENATAUSAHAAN BELANJA LANGSUNG DI PEMERINTAH KABUPATEN MINAHASA SELATAN (STUDI KASUS PADA DINAS SOSIAL TENAGA KERJA DAN TRANSMIGRASI)
}

\author{
Putri Marina Wonggo ${ }^{1}$, Dhullo Affandi ${ }^{2}$, I Gede Suwetja ${ }^{3}$ \\ ${ }^{1,2,3}$ Jurusan Akuntansi, Fakultas Ekonomi dan Bisnis, Universitas Sam Ratulangi, Jl. Kampus Bahu, Manado, \\ 95115, Indonesia \\ E-mail : putriwonggo18@yahoo.com
}

\begin{abstract}
Indirect expenditures represent expenditures that have no direct relationship to the implementation of programs and activities consisting of personnel expenditures, interest expenditures, subsidies, grants, social assistance, revenue-sharing, financial aid expenditures and unexpected expenditures. Direct expenditure is expenditure that has direct relationship with programs and activities which include personnel expenditure, goods and services expenditure and capital expenditure. Local financial management in both revenue (expenditure) and expenditure (expenditure) is very important to note, the weakness of administering the finance of this region resulted in weakness of internal financial control system, at the end will be very low quality of administrative evidence required in accounting record. The administration of regional finance is based on Permendagri number 13 of 2006 concerning the guideline of regional financial management as has been amended into Permendagri Number 59 Year 2007 and the change of the second amendment with the regulation of the Minister of Home Affairs No.21 of 2011. Target of this researchanalyze the adequacy of direct administration system in the Social Service of South Minahasa Regency based on Permendagri Number 21 of 2011.The analytical method used is descriptive analysis.The results showed that the system and procedure of direct administration administration of Social Service of Manpower and Transmigration of South Minahasa Regency has been in accordance with Permendagri Number 21 Year 2011 and the system has been adequate. However, there are still some obstacles faced such as errors of record, as well as procedural errors.
\end{abstract}

Keywords : system, administration, direct spending

\section{PENDAHULUAN}

Akonji et al, (2013) yang menyatakan belanja publik sebagian besar dikendalikan oleh tingkat pertumbuhan ekonomi.Belanja Daerah atau yang dikenal dengan pengeluaran pemerintah derah dalam Anggaran Pendapatan Belanja Daerah (APBD) merupakan salah satu factor pendorong pertumbuhan ekonomi daerah.Mongowal (2013) Belanja daerah adalah semua kewajiban pemerintah daerah yang diakui pengurang nilai kekayaan bersih.Belanja tidak langsung merupakan belanja yang tidak memiliki keterkaitan secara langsung dengan pelaksanaan program dan kegiatan terdiri dari belanja pegawai, belanja bunga, subsidi, hibah, bantuan sosial, belanja bagi hasil, belanja bantuan keuangan dan belanja tak terduga. Belanja langsung merupakan belanja yang memiliki keterkaitan secara langsung dengan program dan kegiatan yang meliputi belanja pegawai, belanja barang dan jasa serta belanja modal.

Penatusahaan Keuangan Daerah baik dari sisi pendapatan (penerimaan) maupun sisi belanja (pengeluaran) sangatlah penting untuk diperhatikan, kelemahan menatausahakan keuangan daerah ini mengakibatkan lemahnya sistem pengendalian intern keuangan daerah, pada ujungnya akan sangat rendah kualitas bukti-bukti administrasi yang diperlukan dalam pencatatan akuntansi. Penatausahaan keuangan daerah berpedoman pada Permendagri nomor 13 Tahun 2006 tentang pedoman pengelolaan keuangan daerah sebagimana telah diubah 
menjadi Permendagri Nomor 59 Tahun 2007 dan perubahan adanya perubahan kedua dengan peraturan menteri dalam negeri No.21 tahun 2011 yaitu sebagai berikut :

1. Penatausahaan pendapatan pada tingkat Satuan Kerja Perangkat Daerah (SKPD) dan tingkat Satuan Kerja Pengelolaan Keuangan Daerah (SKPKD).

2. Penatausahaan Belanja pada tingkat SKPD dan tingkat SKPKD.

3. Penatausahaan penerimaan dan pengeluaran sebagai pemerintah daerah dan pembiayaan pada tingkat SKPKD.

Satuan Kerja Perangkat Daerah sebagai entitas instansi atau lembaga yang dituntut melakukan pengelolaan keuangan daerah yang mengatur tentang penatausahaan keuangan daerah agar bisa bekerja sesuai peraturan yang telah ditetapkan, dengan maksud kinerja Satuan kerja Perangkat Daerah memiliki kemampuan akuntabilitas dan optimalisasi pengelolaan dan pertanggung jawaban keuangan yang berkualitas pada setiap satuan kerja berbasis standar akuntansi pemerintahan yang secara progresif berkelanjutan mereflesikan suatu keinginan mencapai transparansi yang berterima umum.Dinas sosial tenaga kerja dan transmigrasi kabupaten Minahasa selatan salah satu SKPD (Satuan Kerja Perangkat Daerah) dari segi pelaksanaan anggaran, pendapatan dan belanja lebih dominan dari segi pengangarannya adalah kompenen belanja daripada pendapatan, sementara di dalam pelaksanaan belanja itu mulai penganggaran sampai pengeluaran ada suatu prosedur penatausahaan yang harus di laksanakan. Namun sampai sejauh mana penatausahaan belanja langsung dapat dilaksanakan sesuai yang di tetapkan.Maka penulis tertarik untuk melakukan penelitian mengenai"Analisis Sistem Penatausahaan Belanja Langsung Di Pemerintah Kabupaten Minahasa Selatan (Studi Kasus Pada Dinas Sosial Tenaga Kerja dan Transmigrasi ".

\section{TINJAUAN PUSTAKA}

\subsection{Konsep Akuntansi}

Menurut Americon Accounting Association Akuntansi adalah suatu proses mengidentifikasi, mengukur, dan melaporkan informasi ekonomi untuk memungkinkan adanya penilaian dan keputusan yang jelas serta tegas bagi pihak yang menggunakan informasi tersebut.Menurut Mardiasmo (2014:1) Akuntansi adalah seni pencatatan, penggolongan, peringkasan, dan pelaporan transaksi-transaksi keuangan suatu organisasi dengan cara-cara tertentuyang sistematis, serta penafsiran terhadap hasilnya.Pontoh, (2013:8) menyatakan akuntansi adalah sebuah sistem informasi yang dirancang oleh sebuah organisasi untuk mengidentifikasi (analisis, mancatat, dan meringkas) aktivitas-aktivitas yang mempengaruhi kondisi dan kinerja keuangannya, kemudian mengkomunikasikan hasilnya kepada pengambil keputusan, baikdari internal maupun eksternal organisasi.

\subsection{Sistem informasi Akuntansi}

Sistem informasi terutama banyak berhubungan dengan kegiatan operasional dalam perusahaan, Karena dengan adanya sistem informasi ini akan mengurangi keraguan manajer dalam pengambilan keputusan untuk memecahkan masalah yang akan dihadapi. Dimana hal ini berarti bahwa sistem itu akan melibatakan semua sumber-sumber daya yang ada di dalam perusahaan dalam pencapaian tujuan perusahaan.Menurut Mulyadi (2016) sistem adalah suatu jaringan prosedur yang dibuat menurut pola yang terpadu untuk melaksanakan kegiatan pokok perusahaan.

\subsection{Sistem Akuntansi Pemerintahan Pusat (SAPP)}

Sistem Akuntansi Pemerintahan adalah serangkaian prosedur baik manual maupun komputerisasi mulai dari pengumpulan data, pencatatan, pengikhtisaran sampai pelaporan posisi keuangan dan operasi keuangan pemerintah pusat.Ruang lingkup SAPP adalah 
pemerintah pusat (dalam hal ini adalah lembaga tinggi Negara dan lembaga eksekutif) serta pemerintah daerah yang mendapat dana dari APBN (terkait dengan dana dekonsentrasi dan dana tugas pembantuan). Oleh karena itu, SAPP tidak dapat diterapkan untuk lingkungan pemerintah daerah (yang menggunakan APBD).

\subsection{Sistem Akuntansi Pemerintah Daerah (SAPD)}

Sistem Akuntansi Pemerintah Daerah meliputi serangkaian prosedur mulai dari proses pengumpulan data/bukti transaksi keuangan, pencatatan, pengklasifikasian, pengihktisaran sampai pelaporan keuangan dalam rangka pertanggungjawaban pelaksanaan APBD, ynag dapat dilakukan secara manual dengan menggunakan aplikasi komputer.

SAPD sekurang-kurangnya meliputi prosedur akuntansi penerimaan kas,prosedur akuntansi pengeluaran kas, prosedur akuntansi asset tetap/barang milik daerah dan prosedur akuntansi selain kas.

\subsection{Sistem pengeluaran kas}

Sistem pengeluaran kas adalah serangkaian proses mulai pencatatan, penggolongan dan peringkasan transaksi dan/atau kejadian keuangan serta pelaporan keuangan dalam rangka pertanggungjawaban pelaksanaan APBD yang berkenaan dengan pengeluran kas pada SKPKD dan/atau pada SKPD yang dapat dilaksanakan secara manual maupun terkomputerisasi.

\subsection{Konsep Belanja Pemerintah Daerah}

Belanja pada pemerintah daerah terbagi atas Kelompok belanja tidak langsung merupakanbelanja yang di anggarkan tidak terkait secara langsung dengan pelaksanaan program dan kegiatan. Kelompok belanja langsung merupakan belanja yang dianggarkan terkait secara langsung dengan pelaksanaan program dan kegiatan.Aremu, et al (2015) Belanja pemerintah di berbagai sektor memiliki khasiat yang berbedaterhadap pertumbuhan ekonomi.Standar Akuntansi Pemerintahan (SAP) menyatakan bahwa belanja diakui pada saat terjadinya pengeluaran dari rekening kas umum Negara/ Daerah.

\section{Belanja Langsung}

Chude (2013) menyatakan bahwa realisasi belanja langsung diasumsikan berpengaruh positif terhadap pertumbuhan ekonomi. Belanja langsung terdiri dari sebagai berikut :

1. Belanja Pegawai Belanja yang digunakan untuk pengeluaran honorium atau upah dalam melaksanakan program dan kegiatan pemerintah daerah

2. Belanja Barang dan Jasa

Belanja yang digunakan untuk menganggarkan pengadaan barang dan jasa yang nilai manfaatnya kurang dari 12 bulan dalam melaksanakan program dan pemerintah daerah berupa belanja habis pakai,jasa kantor, premi asuransi, perawatan kendaraan bermotor, cetak/ pengadaan, sewa rumah/ gedung/ gudang parker, sewa sarana mobilitas, sewa alat berat, sewa perlengkapan dan peralatan kantor, makanan, minuman, pakaian dinas dan atributnya, pakaian kerja, pakaian khusus dan hari-hari tertentu,perjalanan dinas pindah tugas dan pemulangan pegawai dan belanja lainnya yang sejenis.

3. Belanja Modal

Belanja digunakan untuk pngeluaran yang dilakukan dalam rangka pengadaan asset tetap berwujud yang mempunyai nilai manfaat lebih dari 12 bulan untuk digunakan dalam kegitan pemerintah. 


\section{Penatausahaan Belanja}

Dalam PP No. 71 Tahun 2010 dan Permendagri No. 21 tahun 2011 menyatakan Pengguna Anggaran/Kuasa Pengguna Anggaran, Bendahara Penerimaan atau Bendahara Pengeluaran dan orang atau badan yang menerima atau menguasai uang/barang/kekayaan daerah wajib menyelenggarakan penatausahaan sesuai dengan peraturan perundangundangan.Dalam hal dokumen SPP dinyatakan lengkap dan sah Pengguna Anggaran/Kuasa Pengguna Anggaran menerbitkan SPM.Penerbitan yang dimaksud adalah penandatanganan (otorisasi) sedangkan pembuatan SPM dilakukan oleh PPK SKPD. Karena dokumen atau media tersebut berkaitan dengan dasar pembayaran oleh BUD menimbulkan kewajiban untuk menatausahakan dan media yang digunakan adalah sebagai berikut :

1. Register SPD

Merupakan buku yang digunakan oleh bendaharawan untuk mencatat SPD yang diterima SKPD selama pelaksanaan anggaran. Jumlah register SPD yang dibuat oleh Bendaharwan Pengeluaran tergantung dari sistem penerbitan SPD yang dikeluarkan oleh Pejabat Pengelola Keuangan Daerah.

2. Register SPP

Adalah register yang digunakan oleh Bendahara Pengeluaran untuk mencatat SPP yang disampaikan oleh Bendahara Pengeluaran Kepada Pengguna Anggaran/Kuasa Pengguna Anggaran. Register yang dibuat di tandatangani oleh Bendahara Pengeluaran, sedangkan register SPP yang dibuat oleh PPK SKPD ditandatangani oleh PPK. Kedua register tersebut diotorisasi/ diketahui oleh Pengguna Anggaran.

3. Register SPM

Adalah buku yang digunakan untuk mencatat SPM yang diterbitkan oleh Pengguna Anggaran/Kuasa Pengguna Anggaran. Karena pembuatan SPM dilakukan oleh PPKSKPD maka pencatatan dalam register SPM dilakukan oleh PPK SKPD.

\subsection{Penelitian Terdahulu}

1. Penelitian yang dilakukan Gabriella (2016) hasil penelitian sistem pencatatan belanja langsung pada Dinas PU Kabupaten Minahasa Tenggara telah memadai. Pimpinan Dinas PU Kabupaten Minahasa Tenggara sebaiknya mempertahankan pencatatan belanja langsung yang sudah memadai, dan yang belum memadai diperbaiki.

2. Penelitian yang dilakukan Eni (2016) hasil penelitian Pengelolaan keuangan Dinas kesehatan seperti struktur organisasi, perencanaan, pelaksanaan, pencatatan/pembukuan, klasifikasi, kebijakan akuntansi dan pelaporan dalam hal belanja sudah sesuai dengan Peraturan Menteri Dalam Negeri Nomor 21 Tahun 2011 dan Peraturan Pemerintah Nomor 71 Tahun 2010.

\section{METODE PENELITIAN}

\subsection{Jenis dan Sumber Data}

Jenis data yang digunakan adalah data Kualitatifyaitu data yang tidak dapat diukur dalam skala angka, cara penyajian data secara deskriptif (Kuncoro 2014:145) yakni dokumen, prosedur, informasi tentang Sistem Penatausahaan Belanja Langsung di Dinas Sosial Tenaga Kerja dan Transmigrasi.

\subsection{Metode Analisis Data}

Metode yang dipakai dalam penelitian ini adalah metode deskriptif yaitu melakukan identifikasi prosedur penatausahaan yang berlangsung di skpd, dokumen yang digunakan sehubungan dengan komponen-kompenen belanja langsung yang ada di Dinas Sosial Kabupaten Minahasa Selatan hasil identifikasi tersebut kemudian dibandingkan dengan konsep sistem, perbandingan yang telah di identifikasi ditarik kesimpulannya. 


\section{HASIL ANALISIS DAN PEMBAHASAN}

\subsection{Hasil Analisis}

\section{Sistem dan Prosedur Belanja Langsung pada Dinas Sosial Tenaga Kerja dan Transmigrasi Kabupaten Minahasa Selatan}

Sistem Akuntansi SKPD merupakan serangkaian prosedur manual maupun yang terkomputerisasi mulai dari pengumpulan data, pencatatan, pengikhtisaran sampai dengan pelaporan posisi keuangan dan operasi keuangan, di SKPD. Prosedur akuntansi Belanja lansung, yaitu serangkaian proses baik manual maupun secara komputerisasi, dimulai dari pencatatan transaksi serta pengikhtisarannya sampai dengan pelaporan keuangan dalam rangka mempertanggungjawabkan pelaksanaan APBD yang terkait dengan Belanja. Sistem dan prosedur belanja langsung yang diterapkan pada Dinas Sosial Tenaga Kerja dan Transmigrasi Kabupaten Minahasa Selatan dalam pelaksanaan Belanja Langsung yaitu sebagai berikut :

1. Penerbitan Surat Penyediaan Dana (SPD)

Kuasa BUD Menganalisa DPA-SKPD yang ada dalam database dan menganalisa anggaran kas pemerintah khususnya Dinas Sosial Tenaga Kerja dan Transmigrasi Kabupaten Minahasa Selatan selaku SKPD, menyiapkan draft SPD dan mendistribusikan SPD kepada para pengguna anggaran.Selanjutnya, PPKD bertugas menelitu draft SKPD yang telah diajukan kuasa BUD dan melakukan otorisasi SPD.

2. Pengajuan Surat Permintaan Pembayaran (SPP)

Pengajuan Surat Permintaan Pembayaran (SPP) untuk penerbitan SPM, berdasarkan SPD yang diterima pengguna anggaran dari PPKD selaku BUD, Bendahara Pengeluaran mengajukan Surat Permintaan Pembayaran kepada pengguna anggaran/kuasa pengguna anggaran melalaui Pejabat Penatausahaan keuangan SKPD. Bendahara Pengeluaran mengajukan Surat Permintaan Pembayaran (SPP) dalam belanja. Disamping membuat SPP, Bendahara Pengeluaran juga membuat register untuk SPP yang diajukan, dan register SPM dan SP2D yang sudah diterima oleh bendahara.

3. Penerbitan Surat Perintah Membayar (SPM)

Tahapan penting dalam penatausahaan pengeluaran yang merupakan tahap lanjutan dari proses pengajuan SPP. Sebagai tahap lanjutan, SPM juga dibedakan menjadi 4 (empat) sesuai dengan jenis SPPnya, yaitu SPM UP, GU, TU dan LS. Proses ini dimulai dengan pengujian atas SPM yang diajukan baik dari segi kelengkapan dokumen maupun kebenaran pengisiannya. Untuk SPM GU, pengujian juga dilakukan atas SPJ yang diajukan oleh bendahara. Begitu juga untuk SPM TU jika sebelumnya telah pernah dilakukan.

4. Penerbitan Surat Perintah Pencairan Dana (SP2D)

Setelah SPM diterima oleh BUD selanjutnya menerbitkan Surat SP2D yang diguanakn untuk mencairkan dana lewat bank yang telah ditunjuk. SP2D adalah spesifik.Penerbitan SP2D paling lambat 2 hari kerja sejak SPM-UP/GU/TU/LS diterima. Apabila ternyata kuasa BUD menyatakan bahwa dokumen yang diperlukan belum lengkap, maka kuasa BUD membuat surat penolakan penerbitan SP2D dalam dua rangkap. Satu dokumen diberikan kepada PPKD yang kemudian akan diberikan pada pengguna anggaran agar menyempurnakan SPM, sementara yang satu akan diarsipkan dalam Register surat penolakan penerbitan SP2D. Proses penolakan SP2D dilakukan paling lambat 1 hari kerja sejak SPM diterima.

Bendahara pengeluaran berdasarkan dokumen yang diberikan oleh PPTK, mencatat pelaksanaan belanja ls kedalam pembukuan.Dalam pelaksanaannya, tidak semua dokumen pembukuan digunakan secara bersamaan untuk membukukan satu transaksi keuangan yang dilakukan oleh bendahara pengeluaran. 


\section{Tata Cara Penatausahaan Bendahara Pengeluaran}

Setelah disahkannya anggaran SKPD yang termuat dalam DPA-SKPD, selanjutnya adalah pelaksanaan program kerja SKPD sesuai dengan RKA (Rencana Kerja Anggaran).Sehubungan dengan penerbitan SPD (Surat Penyediaan Dana) oleh BUD (Bendahara Umum Daerah), hal pertama yang dilakukan oleh bendahara pengeluaran adalah mengajukan SPP (Surat Permintaan Pembayaran) kepada pengguna anggaran melalui Pejabat Penatausahaan Keuangan (PPK) SKPD.Jika SPP telah diverifikasi dan diotorisasi oleh pengguna anggaran, tahapan selanjutnya adalah penerbitan Surat Perintah Membayar (SPM) oleh Pejabat Penguna Anggaran.SPM yang telah ditandatangani kemudian diajukan kepada BUD.Dokumen pencairan dana dari BUD berupa SP2D (Surat Perintah Pencairan Dana) yang diterima bendahara pengeluaran untuk membiayai belanja atas kegiatan-kegiatan dan program kerja SKPD. Tugas dan kewenangan bendahara pengeluaran dalam hal ini yaitu pengajuan SPP dan penerimaan SP2D. Selain itu bendahara pengeluaran juga membuat register untuk SPP yang diajukan, SPM, dan SP2D yang sudah diterima oleh bendahara pengeluaran.Gambar 4.2 menunjukkan dokumen dokumen yang digunakan oleh bendahara pengeluaran, dimulai dari SPD hingga pembuatan SPJ.

\section{Dokumen yang digunakan}

\section{Pengajuan Surat Permintaan Pembayaran (SPP)}

Bendahara pengeluaran Dinas Sosial Tenaga Kerja dan Transmigrasi Kabupaten Minahasa Selatan mengajukan SPP dalam rangka melaksanakan belanja.Dokumen SPP ini berupa Uang Persediaan (SPP-UP), Ganti Uang (SPP-GU), Tambah Uang (SPP-TU) dan Langsung (SPP-LS). Dalam Peraturan Pemerintah, SPP yang diajukan ini harus diverifikasi oleh PPK, tetapi dalam penerapannya, bendahara Pengeluaran Dinas Sosial Tenaga Kerja dan Transmigrasi Kabupaten Minahasa Selatanseringkali mengajukan SPP tanpa verifikasi terlebih dahulu melalui PPK seperti yang diatur dalam Permendagri Nomor 21 Tahun 2011.

1. Langsung (SPP-LS)

SPP-LS digunakan untuk pembayaran langsung kepada pihak ketiga dengan jumlah yang telah di tetapkan.Pembayaran langsung digunakan untuk belanja pegawai berupa gaji dan tunjangan, serta belanja untuk pengadaan barang dan/atau jasa.

1. LS untuk pembayaran gaji dan tunjangan

Bendahara menyiapkan dokumen-dokumen seperti salinan SPD, draft surat pernyataan pengguna anggaran, dokumen-dokumen pelengkap daftar gaji, lampiran lain yang diperlukan.

2. LS untuk pengadaan barang dan/atau jasa

Bendahara menyiapkan dokumen-dokumen seperti, salinan SPD, draf surat pernyataan pengguna anggaran, dokumen-dokumen terkait kegiatan yang dalam hal ini disiapkan oleh PPTK, dan lampiran lain yang diperlukan. Dokumen-dokumen yang disiapkan bendahara pengeluaran Dinas Sosial Tenaga Kerja dan Transmigrasi Kabupaten Minahasa Selatan untuk pengajuan SPP-LS ini sudah sesuai Permendagri Nomor 21 Tahun 2011.

3. Pembukuan Penerimaan SP2D LS

Dalam pembukuan penerimaan SP2D LS ini terbagi atas dua tahap yaitu pembukuan gaji dan tunjangan dan pembukuan saat pengadaan barang dan jasa. Pembukan atas SP2D LS untuk pembayaran gaji dan tunjangan dimulai ketika bendahara pengeluaran Dinas Sosial Tenaga Kerja dan Transmigrasi Kabupaten Minahasa Selatan menerima SP2D LS gaji dari BUD melalui Kepala Dinas, pembukuan dilakukan sebesar jumlah belanja bruto sebagai belanja gaji dan tunjangan di BKU pada kolom penerimaan dan pengeluaran juga pada buku pembantu rincian objek belanja pada kolom belanja LS (kode rekening menyesuaikan dengan 
yang tercantum dalam SP2D).

Pada tahap ini bendahara pengeluaran Dinas Sosial Tenaga Kerja dan Transmigrasi Kabupaten Minahasa Selatan sudah melakukan pencatatan dengan benar di BKU sesuai denganPermendagri Nomor 21 Tahun 2011.

Selanjutnya pembukuan untuk pengadaan barang dan jasa, dimulai ketika bendahara pengeluaran menerima SP2D LS barang dan jasa dari BUD melalui pengguna anggaran.Ketika SP2D LS diterbitkan, BUD langsung membayar belanja atas kegiatan pengadaan barang dan jasa kepada penyedia barang dan jasa.Bendahara pengeluaran membukukan dengan jumlah belanja bruto sebagai pengadaan pada buku berikut.

1. BKU pada kolom penerimaan dan pengeluaran pada tanggal yang sama

2. Buku pembantu rincian objek belanja yang terkait pada kolom belanja LS

Potongan pajak yang dikenakan dalam belanja pengadaan barang dan jasa, bendahara pengeluaran akan melakukan pembukuan sebesar jumlah pajak yang dipungut/dipotong sebagai pemungutan/pemotongan $\mathrm{PPh} / \mathrm{PPN}$ di BKU pada kolom penerimaan dan kolom pengeluaran pada tanggal yang sama dan buku pembantu pajak kolom penerimaan dan kolom pengeluaran pada tanggal yang sama. Berdasarkan penelitian yang dilakukan, menunjukkan bahwa pada proses pembukuan pengadaan barang dan jasa ini juga sudah dilakukan bendahara pengeluaran Dinas Sosial Tenaga Kerja dan Transmigrasi Kabupaten Minahasa Selatan sesuai dengan Permendagri Nomor 21 Tahun 2011.

\subsection{Pembahasan}

Penerbitan Surat Penyediaan Dana (SPD) yang menyatakan terjadinya dana untuk melaksanakan kegiatan sebagai dasar dari penerbitan SPP. SPD digunakan untuk menyediakan dana bagi tiap-tiap SKPD termasuk pada Dinas Sosial Tenaga Kerja dan Transmigrasi Kabupaten Minahasa Selatan dalam waktu tertentu. Informasi dalam SPD menunjukkan secara jelas alokasi tiap kegiatan.SPD yang diterbitkan terdiri atas lembar SPD adalah Surat Penyediaan Dana, yang dibuat oleh BUD (Bendahara Umum Daerah) dalam rangka manajemen kas daerah. SPD digunakan untuk menyediakan dana. Informasi dalam SPD menunjukkan secara jelas alokasi tiap kegiatan yang akan dilaksanakan oleh Dinas Sosial Tenaga Kerja dan Transmigrasi Kabupaten Minahasa Selatan.

\section{Penerbitan SPD (LS) \\ PPKD}

Dalam kegitan ini mempunyai tugas: Meneliti draft SPD yang diajukan kuasa BUD, Melakukan otorisasi SPP, dan Berdasarkan SPD atau dokumen lain atau yang dipersamakan dengan SPD. Bendahara Pengeluaran mengajukan Surat Permintaan Pencairan Dana (SPP) kepada Pengguna Anggaran/kuasa pengguna anggaran melalaui Pejabat Penatausahaan Keuangan SKPD (PPKSKPD). SPP memiliki 4 jenis yang terdiri dari: SPP Langsung (SPP-LS) :Diperguakan untuk pembayaran pihak ketiga dengan jumlah yang telah ditetapkan. Dinas Sosial Tenaga Kerja dan Transmigrasi Kabupaten Minahasa Selatan SPP-LS dikelompokan menjadi SPP UP/TU/GU/LS. Untuk mekanisme Belanja langsung pada Dinas Sosial Tenaga Kerja dan Transmigrasi Kabupaten Minahasa Selatan dibagi menjadi : SPP-LS Gaji dan Tunjangan 2. SPP-LS Barang dan Jasa, SPPLS Belanja Bunga, Hibah, Bantuan dan Biaya tak terduga dan sesuai dengan Permendagri Nomor 21 Tahun 2011.

2. Pengajuan SPP (LS)

\section{Bendahara Pengeluaran}

Dalam kegiatan ini, Bendahara Pengeluaran mempunyai tugas: Mempersiapkan dokumen SPP beserta lampiran-lampirannya, dan Mengajukan SPP kepada PPK-SKPD.

\section{PPK-SKPD (Pejabat Pengelola Keuangan-SKPD)}

Dalam kegiatan ini, PPK-SKPD mempunyai tugas: Menguji kelengkapan dan kebenaran SPP yang diajukan Bendahara Pengeluaran. 


\section{PPTK (Pejabat Pengelola Teknik Kegiatan)}

Dalam kegiatan ini, PPTK mempunyai tugas: Mempersiapkan dokumen-dokumen yang diperlukan dalam pengajuan SPP-LS Proses Penerbitan Surat Perintah Membayar (SPM) adalah tahapan penting dalam penatausahaan pengeluaran yang merupakan tahap lanjutan dari pengajuan SPP. Pengguna Anggaran berhak membuat surat penolakan SPM yang diterbitkan PP-SKPD bila SPP yang diajukan tidak lengkap.

\section{PPK-SKPD}

Dalam prosedur ini, PPK-SKPD memiliki tugas sebagai berikut: Menguji SPP beserta kelengkapannya. SPP LS Gaji/Barang dan Jasa, SPP TU/GU.Membuat SPM atas SPP yang telah diuji kelengkapan dan kebenarannya dan mengajukannya ke Pengguna Anggaran/Kuasa Pengguna Anggaran.Membubuhkan paraf pada SPM yang telah dibuatnya.Menerbitkan Surat Penolakan SPM bila SPP yang diajukan oleh Bendahara SKPD tidak lengkap.Apabila SPM sudah ditandatangani oleh PA/KPA, maka PPK-SKPD menyampaikan SPM dan sesuai dengan Permendagri Nomor 21 Tahun 2011.

3. Penerbitan SPM (LS)

\section{Pengguna Anggaran/Kuasa Pengguna Anggaran (PA/KPA)}

Dalam prosedur ini, PA/KPA memiliki tugas sebagai berikut: Menandatangani SPM yang telah diparaf oleh PPK-SKPD. Mengotorisasi Surat Penolakan SPM yang diterbitkan PPK SKPD bila SPP yang diajukan bendahara SKPD tidak lengkap.Menyampaikan SPM beserta kelengkapannya yang telah ditandatangani ke DPPKA melalui PPK-SKPD. Setelah Penerbitan SPM Dinas Sosial Tenaga Kerja dan Transmigrasi Kabupaten Minahasa Selatan menerbitkan Surat Peintah Pencairan Dana (SP2D) yang dipergunakan untuk mencairkan dana lewat bank yang ditunjuk setelah SPM diterima oleh BUD.

\section{Kuasa BUD}

Dalam prosedur ini, Kuasa BUD memiliki tugas sebagai berikut: Menerima SPM beserta kelengkapannya dan menandatangani buku ekspedisi dari SKPD melalui seksi Anggaran. Seksi Anggaran melakukan verifikasi atas ketersediaan dana terhadap SPM yang diterima dengan SPD pada Triwulan yang bersangkutan. Apabila anggarannya tersedia, selanjutnya diserahkan kepada Seksi Perbendahraan.Seksi Perbendaharaan meneliti SPM dan kelengkapan dokumen pendukung.Apabila SPM dan kelengkapannya dapat diterima, maka seksi perbendaharaan mencetak SP2D.Menandatangani SP2D yang telah diparaf oleh pejabat yang ditunjuk oleh BUD sebanyak 5 rangkap, paling lama 2 hari kerja setelah diterimanya SPM.

1.Lembar 1 untuk Bank

2.Lembar 2 untuk arsip di Kuasa BUD

3.Lembar 3 untuk PPK-SKPD

4.Lembar 4 untuk seksi pembukuan dan pelaporan di DISNAKERTRANS

5.Lembar 5 untuk Bendahara SKPD

Mengirimkan SP2D kepada bank dan Membuat register SP2D.

Pengguna Anggaran/Kuasa Pengguna Anggaran.

Dalam kegiatan ini, Pengguna Anggaran/Kuasa Pengguna Anggaran memiliki tugas untuk Menandatangani SPM dan sesuai dengan Permendagri Nomor 21 Tahun 2011.

4. Penerbitan SP2D (LS)

\section{Bendahara Pengeluaran SKPD}

Dalam kegiatan ini, Bendahara Pengeluaran SKPD memilki tugas: Mencatat SP2D pada dokumen penatausahaan yang terdiri atas: Buku Pengeluaran, Buku Pembanntu Simpananan Bank, Buku Pembantu Pajak, Buku Pembantu Panjar, dan Buku Rekapitulasi Pengeluaran Perincian Objek. Untuk Belanja Langsung yang dilakukan melalaui mekanisme Akuntansi Belanja LS Dinas Sosial Tenaga Kerja dan Transmigrasi Kabupaten Minahasa Selatan melalaui Bendahara pengeluaran secara administratif wajib 
mempertanggungjawabkan penggunaan anggaran Belanja-Ls kepada kepala SKPD melalui PPK-SKPD paling lambat 10 bulan berikutnya dan sesuai dengan Permendagri Nomor 21Tahun 2011.

Tabel 4.3 Analisis kesesuaian prosedur penatausahaan belanja langsung pada Dinas Sosial Tenaga Kerja dan Transmigrasi Kabupaten Minahasa Selatan

\begin{tabular}{|c|c|}
\hline $\begin{array}{l}\text { PenerapanProsedur } \\
\text { Penatausahaanbelanja } \\
\text { langsung }\end{array}$ & Analisis Kesesuaian Permendagri \\
\hline \multicolumn{2}{|l|}{ Bendahara Pengeluaran } \\
\hline Penerbitan SPD (LS) & $\begin{array}{l}\text { Dinas Sosial Tenaga Kerja dan Transmigrasi Kabupaten Minahasa Selatan } \\
\text { SPP-LS dikelompokan menjadi SPP UP/TU/GU/LS. Untuk mekanisme } \\
\text { Belanja langsung pada Dinas Sosial Tenaga Kerjadan } \\
\text { TransmigrasiKabupaten Minahasa Selatan dibagi menjadi : SPP-LS Gaji } \\
\text { dan Tunjangan 2. SPP-LS Barang dan Jasa, SPP-LS Belanja Bunga, Hibah, } \\
\text { Bantuan dan Biaya tak terduga dan sesuai dengan Permendagri Nomor } 21 \\
\text { Tahun 2011. }\end{array}$ \\
\hline Pengajuan SPP (LS) & $\begin{array}{l}\text { Dalam prosedur ini, PPK-SKPD memiliki tugas sebagai berikut: Menguji } \\
\text { SPP beserta kelengkapannya.SPP LS Gaji/Barang dan Jasa, SPP TU/GU. } \\
\text { Membuat SPM atas SPP yang telah diuji kelengkapan dan kebenarannya dan } \\
\text { mengajukannya ke Pengguna Anggaran/Kuasa Pengguna Anggaran. } \\
\text { Membubuhkan paraf pada SPM yang telah dibuatnya. Menerbitkan Surat } \\
\text { Penolakan SPM bila SPP yang diajukan oleh Bendahara SKPD tidak lengkap. } \\
\text { Apabila SPM sudah ditandatangani oleh PA/KPA, maka PPK-SKPD } \\
\text { menyampaikan SPM dan sesuai dengan Permendagri Nomor } 21 \text { Tahun } 2011 \text {. }\end{array}$ \\
\hline Penerbitan SPM (LS) & $\begin{array}{l}\text { Dalam kegiatan ini, Pengguna Anggaran/Kuasa Pengguna Anggaran } \\
\text { memiliki tugas untuk Menandatangani SPM dan sesuai dengan Permendagri } \\
\text { Nomor } 21 \text { Tahun } 2011 \text {. }\end{array}$ \\
\hline Peneribitan SP2D (LS) & $\begin{array}{l}\text { Mencatat SP2D pada dokumen penatausahaan yang terdiri atas: Buku } \\
\text { Pengeluaran,Buku Pembanntu Simpananan Bank, Buku Pembantu Pajak, } \\
\text { Buku Pembantu Panjar, dan Buku Rekapitulasi Pengeluaran Perincian } \\
\text { Objek. Untuk Belanja Langsung yang dilakukan melalaui mekanisme } \\
\text { Akuntansi Belanja LS Dinas Sosial Tenaga Kerja dan Transmigrasi } \\
\text { Kabupaten Minahasa Selatan melalaui Bendahara pengeluaran secara } \\
\text { administrative wajib mempertanggungjawabkan penggunaan anggaran } \\
\text { Belanja-Ls kepada kepala SKPD melalui PPK-SKPD paling lambat } 10 \\
\text { bulan berikutnya dan sesuai dengan Permendagri Nomor 21 Tahun } 2011 \text {. }\end{array}$ \\
\hline
\end{tabular}

\section{KESIMPULAN DAN SARAN}

\subsection{Kesimpulan}

Berdasarkan hasil penelitian dan pembahasan maka dapat diambil kesimpulan bahwa Dinas Sosial tenaga kerja dan transmigrasi Kabupaten Minahasa Selatan selaku SKPD telah melaksanakan prosedur penatausahaan belanja langsung, dokumen yang digunakan sampai pada penyusunan laporan pertanggungjawaban bendahara pengeluaran serta penyampainnya sesuai dengan peraturan yang berlaku hal ini berpatokan pada Peraturan Menteri Dalam Negeri Nomor 21 tahun 2011 dan sistem penatausahaan belanja Ls telah memadai.Meskipun masih terdapat Masalah-masalah yang dihadapi Dinas Sosial tenaga kerja dan transmigrasi Kabupaten Minahasa Selatan dalam melaksanakan Permendagri Nomor 21 Tahun 2011 yaitu seperti kesalahan pencatatan, prosedur yang tidak sesuai peraturan. 


\subsection{Saran}

Berdasarkan hasil penelitian dan kesimpulan yang telah diuraikan, maka peneliti menyarankan sebagai berikut:

1.Kepala Dinas Sosial Tenaga kerja dan transmigrasi Kabupaten Minahasa Selatan harus melakukan pengawasan yang lebih ketat lagi agar sistem dan prosedur penatausahaan belanja lebih efektif khususnya belanja langsung.

2.Diharapkan adanya pelatihan dalam bidang akuntansi agar proses kinerja dapat berjalan sesuai yang diharapkan.

3.Sekiranya Penelitian ini dapat menjadi bahan acuan bagi penelitian selanjutnya agar dapat meneliti analisis penatausahaan belanja langsumg secara lebih rinci lagi sehingga selalu ada perubahan kearah yang lebih baik.

\section{DAFTAR PUSTAKA}

Akonji, D. A., Olubukola, O. A., and Wakili, A. M. 2013.Nexus Between Public Expenditure and Economic Growth By Testing Wagner's Law Time Series : Evidence From Nigeria. Internasioanl Journal of Development and Sustainability. Vol. 2(4): 23832395.

Azhar Susanto. 2013. Sistem Informasi Akuntansi. Bandung: Lingga Jaya.

Chude, N. P., and Chude,D. I. 2013.Impact of Government Expenditure on Economic Growth in Nigeria. Internasional Journal of Business and Management Review. Vol. 1(4): 6471.

Kuncoro, Mudrajad, 2014. Metode Riset Untuk Bisnis, dan Ekonomi. Edisi 4 Erlangga. Jakarta.

Mardiasmo, 2014. Akuntansi Keuangan Dasar 1. CetakanKeempat. BPFE, Yogyakarta.

Mulyadi. 2016. Sistem Akuntansi Edisi Keempat. SalembaEmpat : Jakarta.

Mongowal, Christine Jessi 2013.Pendapatan Daerah Pengaruhnya Terhadap Belanja Modal Pada Pemerintah Provinsi Sulawesi Utara. Jurnal EMBA. Vol. 1.No. 4.

Pontoh, Winston. 2013. Akuntansi Konsep dan Aplikasi. Halaman Moeka, Jakarta Barat.

Peraturan Pemerintah Dalam Negeri Nomor 21 Tahun 2011. Pedoman Pengelolaan Keuangan Daerah. Fokus Media Bandung.

Peraturan PemerintahRepublik Indonesia Nomor 71 tahun 2010.StandarAkuntansi Pemerintahan Berbasis Akrual. Salemba Empat. Jakarta.

Pandoh, Fiolita Gabriella. 2016. Evaluasi Sistem Pencatatan Belanja Langsung Pada Dinas Pekerjaan Umum Kabupaten Minahasa Tenggara. Jurnal EMBA. Vol. 4 No. 1 Maret 2016, Hal.1097-1106.

Parayanti, Eni. 2015. Evaluasi Sistem dan prosedur Akuntansi BelanjaPada Satuan Kerja Perangkat Daerah Dinas Kesehatan Provinsi Sulawesi Utara. Jurnal EMBA. Vol. 3.No. 3 Sept. 2015, Hal.608-618.

Pura, Rahman. 2013. PengantarAkuntansi I Pendekatan Siklus Akuntansi .Penerbit Erlangga. Jakarta.

Ratmono, D \& M, Sholihin. 2015. Akuntansi Keuangan Daerah Berbasis Akrual. UPP STIM $Y K P N$, Yogyakarta.

Sitepu, Gloria Esthephany 2015. Analisis Pencatatan dan Pelaporan Belanja Modal Pada Direktorat Jenderal Cipta Karya Dinas Pekerjaan Umum Provinsi Sulawesi Utara. Jurnal EMBA Vol.3 No.4. 